\title{
Indigenous Management of Pain Abdomen- Abdominal Wall Strangulation
}

\author{
${ }^{1}$ Dr Krishna Kumar Mallick, ${ }^{2}$ Somshekhar Sharma, \\ ${ }^{1}$ Associate professor of Surgery Unit, Faculty of Medicine, AIMST University, Malaysia \\ ${ }^{2}$ Medical officer, MGM Medical College, Kamothe, Navi Mumbai, India
}

\begin{abstract}
A case report of unique strangulation of anterior wall in women of 55 years, as a result of some indigenous method of treatment of pain abdomen in rural area of Nepal is reported. The case report is unique and rare incidence of strangulation of abdominal wall due to application of indigenous management practice and highlights its hazardous effect. The case report is of utmost importance to disseminate the awareness amongst the rural and tribal people about the complications of such indigenous treatment practice.
\end{abstract}

Keyword-Strangulation-- Abdominal pain -- Indigenous healing method

\section{INTRODUCTION}

There have been survey reports revealing extensive use of indigenous remedies in the management of common diseases like child diarrhea, fever, many adult diseases like diabetes, obesity, asthma in Indian and Asian countries without formal analytical analysis of medicinal plants or house hold substances, but based on cause effect relationship[1]. In some of the countries, there is drive to identify use of local plants, trees and shrubs together with the part of the plant used and the type of condition treated[2]. The usage of medicinal plants underscores the need for further study of indigenous pharmacopoeias and the therapeutic properties of plants. The role of indigenous plant remedies within local health care systems is also worthy of closer investigation [3]. The present case report is the first of its kind as it is not related with treatment of any medicinal plant or shrub but based on the reported false belief of the rural community on some of their community healer to apply indigenous and irrational treatment practices to manage medical conditions leading to grievous fatal after application of these indigenous modes of treatment. The peculiarity of the present case report is (1) Its peculiar presentation to the hospital and (2) reported false belief of rural people to treat medical conditions without any logical thinking.

\section{CASE REPORT}

A 55 years old woman from kapilvastu, a tarai district of Nepal was brought to the emergency department with complaint of acute pain abdomen and difficulty in passing urine since last 8 hours. On examination, it was seen that a brass pot of about 10 liters capacity was fixed to anterior wall of abdomen. The base of the pot was torn open, through which globular edematous, reddish mass with blisters on surface was visible. The abdomen was found to be distended. Bowel sounds were reduced.

After necessary basic investigations, it was decided that the patient need an immediate surgical intervention as after repeated attempt the pot could not be detached from the abdominal-wall. Accordingly content of fused tissue of abdomen wall with pot was estimated and a transverse incision was applied for over 4 inches above the upper margin of the vessel. The tissue fused with wall of pot was removed with the help of fingers while the part of intestine was gently separated without any damage. Hot towel application helped to treat ischemic loop of the intestine and responded well. A circular incision was applied to remove the pot from abdomen wall alongwith gangrenous \& strangulated part of the abdominal wall. Both the incisions were closed in layers and multiple corrugated drain applied in the suture lines. Recovery from anesthesia was complex but satisfactory. Patient was kept in ICU for 24 hours. Routine investigations and ultrasonography of abdomen was done after patient recovered completely. The ultrasonography findings revealed cholelithiasis alongwith mild degree of cholecystitis. Alternate sutures were removed on $10^{\text {th }}$ and $12^{\text {th }}$ day and patient was discharged with advice of Cholecystectomy after 6-8 weeks. 


\section{DISCUSSION}

Strangulation of anterior wall is rare incidence. In present case, the patient had pain abdomen for last 6 days. The local people burnt some papers in a brass pot till it got extinguished. The hot brass pot was placed tightly over the site of maximum pain over abdomen. After some time the air within the pot got cooled and generated negative pressure, the pot was found almost fused with abdominal wall tightly. Continuous negative pressure within the pot sucked the flabby and fatty abdominal wall inside the pot. Finally, the sucked portion of abdominal wall became edematous due to venous engorgement which led to further fixation of tissue to the mouth of pot, causing strangulation and ischemia of abdominal wall tissue, thus leading to necrosis and gangrene formation.

This case highlights the incidence of an indigenous method of treatment of simple disease i.e. pain in abdomen. The use of present indigenous treatment has caused complications leading to strangulation of abdominal wall without any relief to the patients and finally patient had to resort to the surgical intervention. In present era of information technology, there is need of health education to community to apprise them the fatal complications and undesired trauma attributed to such indigenous healing methods.

Van Crevel et al [4] reported that Amazonian tribal healers use their knowledge about medicinal plant in treatment of some common disease conditions but without any scientific basis. The outcome of these treatment is poorly known and so far there is hardly any report revealing patterns of disease recognition and treatment by Amazonian indigenous healers [5]. We did extensive search for literature regarding the application of various indigenous methods for management of acute abdomen but did not find even a single report. We believe this study will bring about the clinical awareness amongst the community at large and would highlight complications of indigenous method of treatment.

\section{REFERENCES}

[1]. Sharma R.C. at el (2010) Clinical research letters Vol-1, pp

[2]. F. Chinemana,R.B. Drummond, S. Mavi, I. De Zoysa(1985) ; Journal of Ethnopharmacology Volume 14, Issues 2, 159-172

[3]. Balick M, Cox P: Plants, People, and Culture: The Science of Ethnobotany. New York: Scientific American Library; 1997.

[4]. van Crevel R, van Doornick D, van Ams J, Fat H, Vreden S, Meer J: (2004) Nederlands Tijdschrift voor Geneeskunde 2004, 148:425-429.

[5]. Christopher N Herndon, Melvin Uiterloo, Amasina Uremaru, Mark J Plotkin, Gwendolyn Emanuels-Smith and Jeetendra Jitan(2009) Journal of Ethnobiology and Ethnomedicine 2009, 5:27 